\title{
Role of nitric oxide released from iNANC neurons in airway responsiveness in cats
}

\author{
H. Aizawa, S. Takata, H. Inoue, K. Matsumoto, H. Koto, N. Hara
}

Role of nitric oxide released from iNANC neurons in airway responsiveness in cats. $H$. Aizawa, S. Takata, H. Inoue, K. Matsumoto, H. Koto, N. Hara. (C)ERS Journals Ltd 1999. ABSTRACT: The precise role of inhibitory nonadrenergic noncholinergic (iNANC) neurons and nitric oxide in airway hyperresponsiveness remains uncertain. The role of NO in the regulation of airway responsiveness was studied in anaesthetized and mechanically ventilated cats.

To assess airway responsiveness, the changes in total pulmonary resistance $(R \mathrm{~L})$ produced by delivering serotonin aerosol to the airways were measured before and after $N^{\omega}$-nitro-L-arginine methyl ester (L-NAME), or a ganglionic blocker, hexamethonium, which has been reported to block iNANC. Serotonin was chosen because it causes bronchoconstriction in part by neural reflex. To further clarify the mechanism(s) involved, the effect of inhaled capsaicin was also determined in animals with sustained bronchoconstriction induced by serotonin after treatment with atropine and propranolol.

Inhibition of NO synthase by L-NAME or blockade of iNANC neurons by hexamethonium significantly increased airway responsiveness. However, addition of LNAME did not further increase airway responsiveness in animals treated with hexamethonium. In the presence of atropine and propranolol, inhaled capsaicin caused a marked bronchodilation during serotonin-induced sustained bronchoconstriction. The bronchodilation induced by capsaicin was significantly suppressed by hexamethonium and by L-NAME.

These results suggest that the nitric oxide released from inhibitory nonadrenergic noncholinergic neurons is important in modulating the airway responsiveness of cats in vivo.

Eur Respir J 1999; 13: 775-780.
Research Institute for Diseases of the Chest, Faculty of Medicine, Kyushu University, 3-1-1 Maidashi, Higashiku, Fukuoka, Japan.

Correspondence: H. Aizawa

Research Institute for Diseases of the Chest

Faculty of Medicine

Kyushu University

3-1-1 Maidashi, Higashiku

Fukuoka, 812-8582

Japan

Fax: 81926425389

\section{Keywords: Capsaicin}

hexamethonium

$N^{\omega}$-nitro-L-arginine methyl ester

serotonin

reflex bronchodilation

Received: June 231998

Accepted after revision November 171998
Airway hyperresponsiveness is a characteristic feature of asthma. Although the precise mechanism of airway hyperresponsiveness is not known, autonomic regulation of airway smooth muscle must be in part involved [1,2]. Autonomic innervation of the airways consists of adrenergic, cholinergic and nonadrenergic noncholinergic (NANC) nerves [2]. Inhibitory NANC (iNANC) nerves appear to be the principal inhibitory neural mechanism in the airways of a variety of species including humans [3-6]. In human airways, iNANC is considered to be especially important owing to the absence of adrenergic inhibitory innervation [4].

Although the neurotransmitters responsible for the iNANC-mediated relaxation of the airways have not been conclusively identified, nitric oxide is considered a promising candidate [7-11]. In humans and other mammalian species, it has been reported that the inhibition of NO synthase by $N^{\omega}$-nitro-L-arginine methyl ester (L-NAME) produced a concentration-dependent inhibition of iNANCmediated relaxation. Especially in human bronchi, LNAME almost completely abolished iNANC-mediated relaxation, and it was concluded that in human airways $\mathrm{NO}$ is entirely responsible for iNANC-mediated relaxation [9]. In feline airways, NO has also been proposed as the primary mediator of iNANC-mediated relaxation [12]. How- ever, the role of NO released from iNANC nerve terminals in airway responsiveness has not been investigated in the cat. The importance of $\mathrm{NO}$ as an iNANC neurotransmitter in vivo has been reported in a prior study [13]. Electrical vagal stimulation caused a marked decrease in total pulmonary resistance $(R \mathrm{~L})$ during sustained bronchoconstriction in cats treated with atropine and propranolol. The amplitude of the relaxation evoked by vagal stimulation was significantly suppressed by the administration of LNAME [13].

The purpose of this study was to elucidate the mechanism of action of $\mathrm{NO}$ released from iNANC nerves in the regulation of airway responsiveness in the cat in vivo. Changes in airway responsiveness to inhaled serotonin before and after treatment with hexamethodium or LNAME were determined in anaesthetized, mechanically ventilated cats. Serotonin was chosen to assess airway responsiveness, because inhaled serotonin has been reported to cause vagally mediated neural reflex $[14,15]$.

Hexamethonium was used to block iNANC response, because hexamethonium has been reported to abolish iNANC responses evoked by electrical field stimulation [5, $6,16]$. The effects of hexamethonium or L-NAME on the capsaicin-induced inhibition of sustained bronchoconstriction were also determined. 


\section{Methods}

\section{General procedure}

Thirty-six cats (male and female; weight $2-4 \mathrm{~kg}$ ) were anaesthetized with pentobarbital sodium $\left(50 \mathrm{mg} \cdot \mathrm{kg}^{-1}, i . m\right.$. $)$, and ventilated (tidal volume $10 \mathrm{~mL} \cdot \mathrm{kg}^{-1}$; respiratory frequency 30 breaths $\cdot \mathrm{min}^{-1}$ ) with a respirator (model 665 , Harvard Apparatus, South Natick, MA, USA) through a tracheostomy. Airflow was measured by connecting a Fleisch pneumotachograph (TV-142T, Nihon Kohden, Tokyo, Japan) to the tracheal tube. A catheter was inserted through the sixth intercostal space into the pleural cavity (cat in supine position) and was sutured in place after the introduction of 3-5 $\mathrm{mL}$ air. Transpulmonary pressure $(P \mathrm{tp})$ was measured by use of a differential pressure transducer (TP603T, Nihon Kohden) attached to the intrapleural catheter and to a catheter in the tracheal tube [16]. Total $R_{\mathrm{L}}$ was calculated according to the method of AMDUR and MEAD [17].

A catheter was inserted into a carotid artery for the measurement of blood pressure with an electronic manometer (LPU-0.1, Nihon Kohden). Another catheter was inserted into a jugular vein for the administration of drugs.

Airway responsiveness to serotonin was determined by measuring the change in $R \mathrm{~L}$ induced by increasing concentrations of serotonin aerosol administered via the endotracheal tube. Serotonin aerosols $\left(1.5 \mathrm{~mL} \cdot \mathrm{min}^{-1}\right)$ were generated by an ultrasonic nebulizer (TUR-3200, Nihon Kohden), which introduced serotonin aerosol (0.07-1.2 $\mathrm{mg} \cdot \mathrm{mL}^{-1}$ ) into the air supplied by the ventilator. A baseline $R \mathrm{~L}$ value was obtained before exposure to the serotonin aerosol. Cats were then exposed to increasing concentrations of serotonin aerosol and peak $R \mathrm{~L}$ values were obtained for each concentration. Each concentration of serotonin aerosol was administered for 30 breaths. A 5min interval separated each exposure to serotonin aerosol. The provocative concentration was defined as the concentration of serotonin that produced a $200 \%$ increase in $R \mathrm{~L}$ ( $\mathrm{PC} 200)$ and was obtained by interpolation of the plot of serotonin concentration versus $R \mathrm{~L}$. A decrease in this value represented an increase in airway responsiveness to the serotonin aerosol.

\section{Study design}

Effect of L-NAME and/or hexamethonium on airway responsiveness to serotonin aerosol. Serotonin doseresponse curves were measured before and after the drug or vehicle (saline) treatment. For each cat, the first serotonin dose-response curve was measured, followed by an interval of recovery of lung function to baseline values. Then, the drug or vehicle was administered and the second dose-response to serotonin was measured.

To investigate the effect of inhibition of NO synthesis, airway responsiveness was measured before and after intravenous administration of L-NAME $\left(100 \mathrm{mg} \cdot \mathrm{kg}^{-1}\right)$ in five cats. In the previous studies, several doses of L-NAME were used to inhibit NO synthesis. L-NAME $\left(100 \mathrm{mg} \cdot \mathrm{kg}^{-1}\right)$ was chosen, because in cats it was considered to be sufficient to inhibit the synthesis of NO [18-20]. L-NAME was administered by continuous infusion for $30 \mathrm{~min}$ to avoid acute effects on the cardiovascular system. Fifteen minutes after the discontinuation of L-NAME infusion, the experiments were started. To determine whether the effect of L-NAME was due to the inhibition of NO synthesis, the effect of the inactive enantiomer $N^{\omega}$-D-nitro-arginine methyl ester (D-NAME) (at the same dose as L-NAME) on $R \mathrm{~L}$ was examined in five cats. Similarly, to investigate the effect of iNANC blockade by ganglionic blocker $[5,6$, 16], airway responsiveness was measured before and after the administration of hexamethonium $\left(2 \mathrm{mg} \cdot \mathrm{kg}^{-1}, i . v\right.$. $)$ in five cats. In order to verify that the source of NO was iNANC neurons, the effects of L-NAME on airway responsiveness to serotonin was determined in five cats pretreated with hexamethonium. In the beginning of the experiment, all animals were treated with atropine $(2 \mathrm{mg}$. $\mathrm{kg}^{-1}, i . v$.) and propranolol $\left(2 \mathrm{mg} \cdot \mathrm{kg}^{-1}, i . v\right.$. $)$, to control for systemic cholinergic and adrenergic effects.

Effect of L-NAME or hexamethonium on capsaicin-induced bronchodilation. To further elucidate the mechanism by which NO is released from iNANC nerve terminals, the effects of L-NAME on the reflex bronchodilation mediated by iNANC neurons was determined. To induce sustained bronchoconstriction, serotonin $\left(20-80 \mu \mathrm{g} \cdot \mathrm{kg}^{-1} \cdot \mathrm{min}^{-1}\right)$ was infused continuously after the administration of atropine $\left(2 \mathrm{mg} \cdot \mathrm{kg}^{-1}\right)$ and propranolol $\left(2 \mathrm{mg} \cdot \mathrm{kg}^{-1}\right)$. During the resulting bronchoconstriction, capsaicin aerosol $(0.1 \%(\mathrm{w} / \mathrm{v}))$ was administered and the amount of bronchodilation was measured. The effect of L-NAME, D-NAME (100 mg. $\left.\mathrm{kg}^{-1}, i . v ., \mathrm{n}=5\right)$ or hexamethonium $\left(2 \mathrm{mg} \cdot \mathrm{kg}^{-1}, \mathrm{n}=5\right)$ on the bronchodilation induced by capsaicin was determined. Capsaicin aerosols (1.5 $\mathrm{mL} \cdot \mathrm{min}^{-1}$ ) were generated by an ultrasonic nebulizer (TUR-3200, Nihon Kohden) and were administered for five tidal breaths.

\section{Drugs}

Capsaicin, L-NAME, D-NAME, serotonin creatinine, atropine sulphate and propranolol were obtained from Sigma Chemical Co., St Louis, MO, USA, and pentobarbital sodium from Abbot Laboratories, North Chicago, IL, USA.

\section{Statistical analysis}

Values for PC200 are expressed as geometric means (GM) and geometric standard errors of means (GSEM). Values of PC200 obtained before and after treatment with hexamethonium or L-NAME were analysed by the Student's paired t-test. A level of $\mathrm{p}<0.05$ was considered to be statistically significant. Multiple comparison analysis of variance techniques were used to compare the effect of LNAME in the hexamethonium-treated animals, and to compare the effect of L-NAME or hexamethonium on capsaicin-induced bronchodilation.

\section{Results}

Figure 1 shows the reproducibility of the serotonin dose-response curve before and after saline vehicle treatment. PC200 values before and after treatment were not 


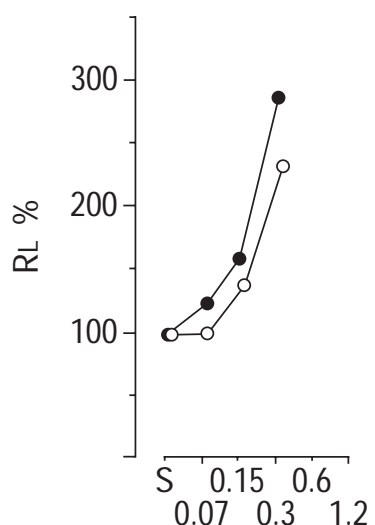

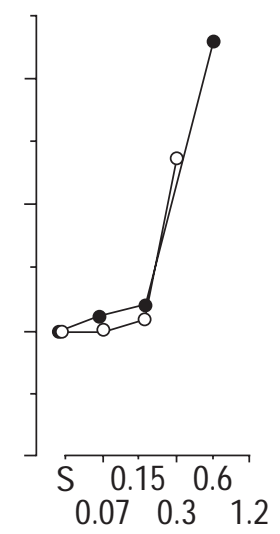

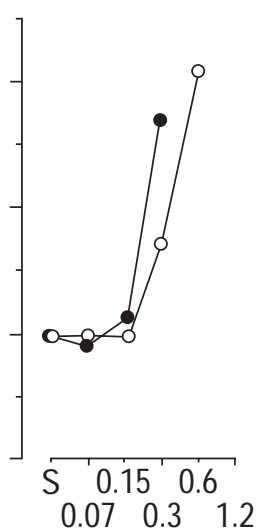

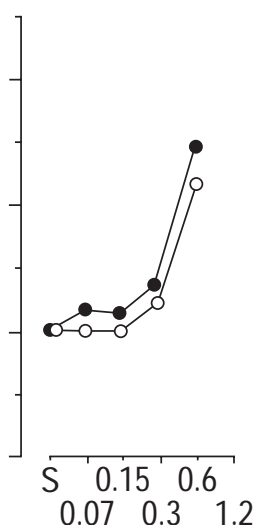

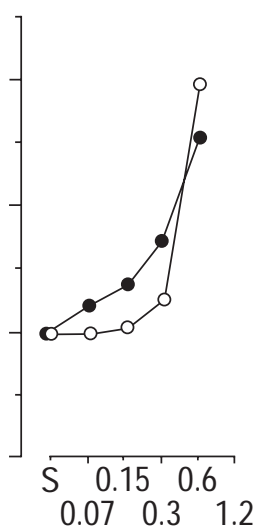

Serotonin $\mathrm{mg} \cdot \mathrm{mL}^{-1}$

Fig. 1. - Dose-response curves to serotonin before $(\bigcirc)$ and after vehicle (saline) treatment $(\bullet)$ in five cats. After the recovery of lung function to baseline values from the first serotonin dose-response curve, saline was administered by continuous infusion for 30 min. Fifteen minutes after discontinuation of saline infusion, a further serotonin dose-response curve was measured.

significantly different at $0.313 \mathrm{mg} \cdot \mathrm{mL}^{-1}$ (GSEM 1.14) and $0.269 \mathrm{mg} \cdot \mathrm{mL}^{-1}$ (GSEM 1.15 ) respectively.

Effect of L-NAME and/or hexamethonium on airway responsiveness to serotonin aerosol

Table 1 shows the $R_{\mathrm{L}}$ and mean systemic blood pressure values. As shown in figure $2 \mathrm{a}$, mean airway responsiveness to serotonin was significantly enhanced by the administration of hexamethonium. L-NAME also increased airway responsiveness to serotonin significantly (fig. 2b). By contrast, D-NAME had no effect on airway response to serotonin, suggesting that the effect of L-NAME was due to the inhibition of NO synthesis (fig. 2c). Although pretreatment with hexamethonium increased mean airway responsiveness to serotonin, no further increase was induced by hexamethonium plus L-NAME (fig. 2d).

Effect of L-NAME or hexamethonium on capsaicin induced bronchodilation

Table 2 shows the $R \mathrm{~L}$ and mean systemic blood pressure values before and after serotonin infusion. Inhalation

Table 1. - Effects of $N^{\omega}$-nitro-L-arginine methyl ester ( $\mathrm{L}-$ NAME), D-NAME, and/or hexamethonium on baseline pulmonary resistance $(R \mathrm{~L})$ and mean systemic blood pressure

\begin{tabular}{lcc}
\hline & $\begin{array}{c}R \mathrm{~L} \\
\mathrm{cmH} \mathrm{O}_{2} \cdot \mathrm{L}^{-1} \cdot \mathrm{s}\end{array}$ & $\begin{array}{c}\text { Blood pressure } \\
\mathrm{mmHg}\end{array}$ \\
\hline Control & $15.1 \pm 1.5$ & $92 \pm 5$ \\
Hexamethonium & $14.9 \pm 2.1$ & $85 \pm 5^{*}$ \\
Control & $15.2 \pm 1.7$ & $90 \pm 4$ \\
L-NAME & $14.7 \pm 1.6$ & $100 \pm 6^{* *}$ \\
Control & $15.0 \pm 1.6$ & $92 \pm 6$ \\
D-NAME & $15.3 \pm 1.7$ & $94 \pm 5$ \\
Control & $15.3 \pm 1.7$ & $93 \pm 5$ \\
Hexamethonium & $14.8 \pm 1.5$ & $86 \pm 5^{*}$ \\
+ L-NAME & $15.2 \pm 1.5$ & $98 \pm 6$ \\
\hline
\end{tabular}

Values are expressed as mean \pm SEM. $*: \mathrm{p}<0.05 ; * *: \mathrm{p}<0.01$ versus control value. $(1 \mathrm{mmHg}=0.133 \mathrm{kPa}$. $)$ of capsaicin decreased $R \mathrm{~L}$ during the sustained bronchoconstriction induced by the continuous serotonin infusion in animals treated with systemic atropine and propranolol (fig. 3). Hexamethonium (fig. 3a) or LNAME (fig. 3b) significantly inhibited the bronchodilation induced by capsaicin. By contrast, D-NAME had no
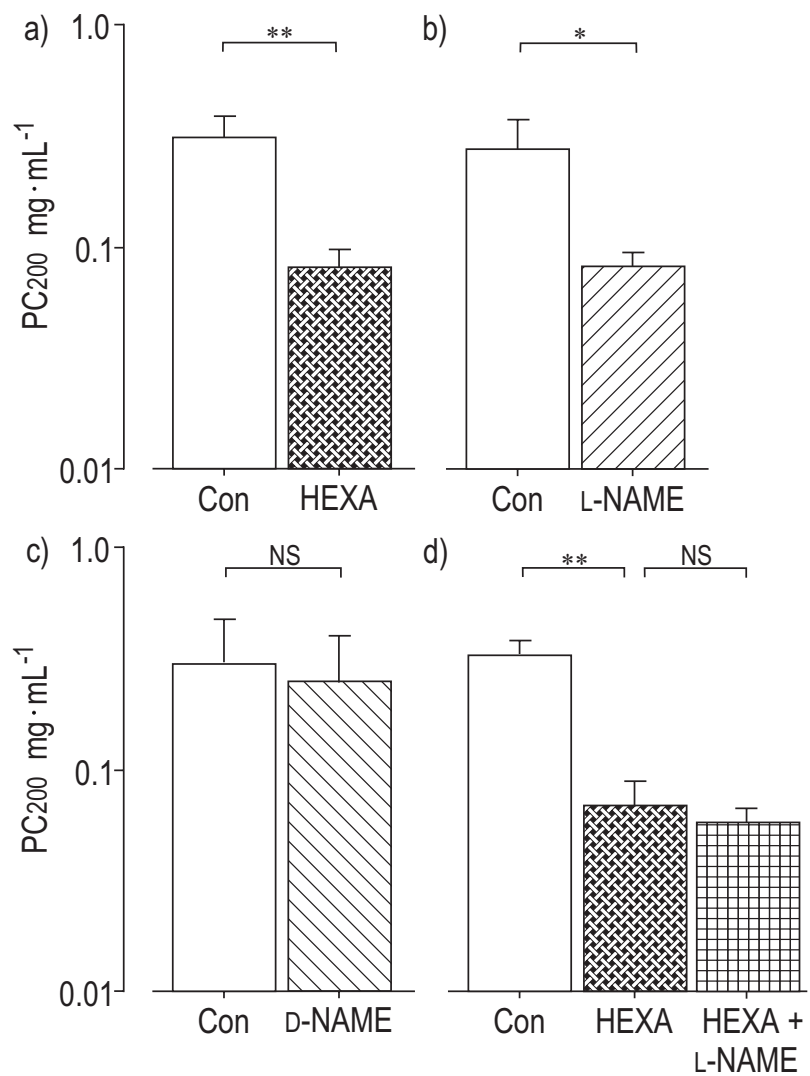

Fig. 2. - Effect of L- $N^{\omega}$-nitro-L-arginine methyl ester (L-NAME), DNAME and/or hexamethonium (HEXA) on mean airway responsiveness to serotonin aerosol in cats. Airway responsiveness is expressed as the concentration of serotonin needed to cause $200 \%$ increase in pulmonary resistance $(\mathrm{PC} 200)$. Data are expressed as geometric means and geometric standard errors of means. a) Hexamethonium ( $n=5)$; b) L-NAME $(\mathrm{n}=5)$; c) D-NAME $(\mathrm{n}=3)$; and d) L-NAME after hexamethonium $(\mathrm{n}=5)$. Con: control. $*$ : $\mathrm{p}<0.05 ; * *: \mathrm{p}<0.01$. 
Table 2. - Effects of serotonin infusion on baseline pulmonary resistance $(R \mathrm{~L})$ and mean systemic blood pressure

\begin{tabular}{lcc}
\hline & $R \mathrm{~L} \mathrm{cmH} \mathrm{Cm}_{2} \mathrm{O} \cdot \mathrm{L}^{-1} \cdot \mathrm{s}$ & Blood pressure $\mathrm{mmHg}$ \\
\hline Control & $15.8 \pm 2.0$ & $94 \pm 6$ \\
Serotonin & $42.3 \pm 5.6^{* *}$ & $90 \pm 7$ \\
\hline
\end{tabular}

Values are expressed as mean \pm SEM. $*$ : $p<0.05 ; * *: p<0.01$ versus control value.

effect on the bronchodilation induced by capsaicin, suggesting that the effect of L-NAME was due to the inhibition of NO synthesis (fig. 3c).

\section{Discussion}

Inhibition of NO synthase by L-NAME significantly increased airway responsiveness to serotonin in the presence of atropine and propranolol, indicating that NO mediates the attenuation of airway responsiveness. Ganglion blockade by hexamethonium, which is reported to block activation of iNANC neurons $[5,6,16]$, significantly increased airway responsiveness to serotonin in the presence of atropine and propranolol, indicating that iNANC activation decreases airway responsiveness. In addition, in cats pretreated with hexamethonium, the failure of LNAME to increase airway hyperresponsiveness was consistent with the hypothesis that NO is released mainly from iNANC nerve terminals.

Inhaled serotonin was chosen to assess airway responsiveness in the present study. It has been reported that inhaled serotonin causes a neural reflex which regulates airway responsiveness. Thus, vagotomy reduced the bronchoconstriction evoked by serotonin in dogs [15], however, it enhanced the bronchoconstriction in cats pretreated with atropine and propranolol [14]. It is assumed that the parasympathetic component in vagal nerve enhances the response to serotonin and the iNANC component reduces the response, because dog airway is not innervated by iNANC. It was also confirmed that the ganglionic blocker hexamethonium enhances the bronchoconstriction evoked by inhaled serotonin in cats. These results indicated that inhaled serotonin causes vagally mediated neural reflex.

In guinea-pigs, inhibition of NO synthesis by L-NAME, enhanced airway responsiveness in vivo and in vitro [21, 22]. Because epithelial denudation diminished the effects of L-NAME, the investigators concluded that the NO responsible for regulating airway responsiveness may be released from airway epithelial cells. However, the results of the present study suggest that the origin of $\mathrm{NO}$ is iNANC neurons because L-NAME did not cause further increase in the airway responsiveness after the inhibition of iNANC neurons by hexamethonium. The reason for this discrepancy is assumed to be due to species differences. In cats, the airways from trachea to bronchiole are innervated with a rich supply of iNANC neurons [8]. Activation of these neurons causes potent bronchodilation of the entire airway in vivo $[5,6,16]$. In guinea-pigs the in vivo studies failed to demonstrate iNANC-mediated bronchodilation $[3,23,24]$ presumably because the guinea-pig airways beyond the main bronchi are innervated with rich excitatory NANC neurons [25-27]. It is suggested that iNANC neurons do not play a key role in the regulation of airway responsiveness in guinea-pigs.

Consistent with previous reports [28, 29], inhalation of capsaicin caused a marked bronchodilation during the bronchoconstriction induced by continuous infusion of serotonin in the presence of atropine and propranolol. This bronchodilation is considered to be mediated by iNANC neurons because it is evoked after blockade of adrenergic and cholinergic receptors. Furthermore, this iNANC-mediated bronchodilation is thought to be part of a reflex mechanism because ganglion blockade completely abolished the effect of capsaicin. L-NAME also completely abolished the capsaicin-induced bronchodilation, suggesting that the neurotransmitter involved in the iNANC reflex mechanism is NO.

The authors' group has previously demonstrated that the iNANC-mediated relaxation of airways induced by electrical stimulation of the vagus nerve can be classified into two components, and that at at least two neurotransmitters are involved in the iNANC-mediated relaxation observed in vivo [13] and in vitro $[8,10]$. The reason other neurotransmitters than NO do not appear to play a role in the

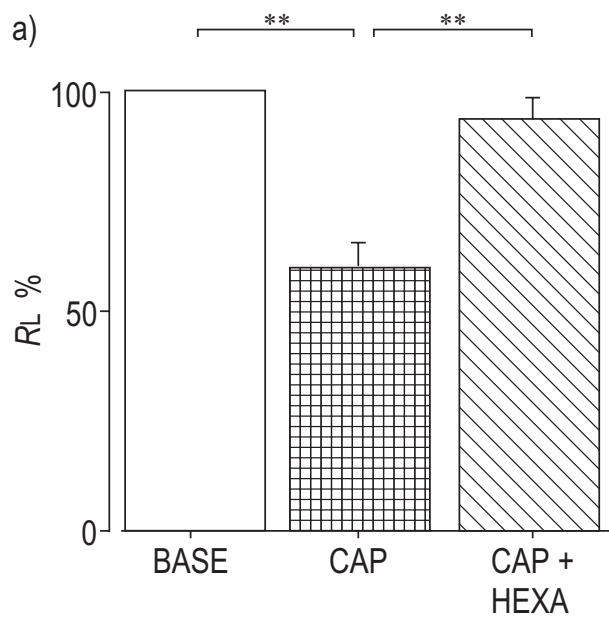

b)

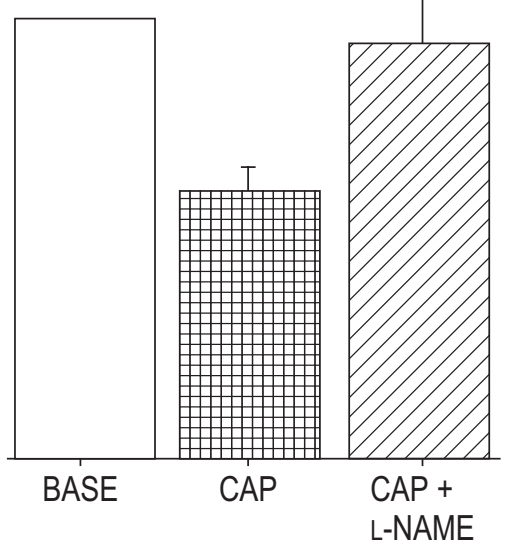

c)
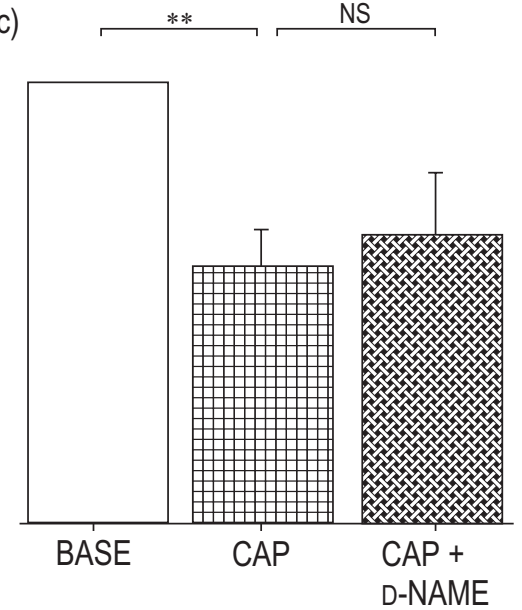

Fig. 3. - Effect of a) hexamethonium (HEXA; $\mathrm{n}=5$ ), b) $N^{\omega}$-nitro-L-arginine methyl ester (L-NAME; $\mathrm{n}=5$ ) or c) D-NAME (n=3) on the bronchodilation induced by inhalation of capsaicin (CAP) aerosol during sustained bronchoconstriction induced by serotonin infusion in cats. Atropine and propranolol were administered (i.v.) prior to treatment with the drugs. Data are represented by the mean \pm SEM of values. BASE: baseline. ${ }^{*}: \mathrm{p}<0.05 ; * *$ : $<<0.01$. 
reflex bronchodilation is unclear. One possible explanation is that the threshold for releasing NO is different from the threshold for release of other transmitters. In fact, in the bronchiole, single electrical field stimulation with short pulse duration evoked initial fast and L-NAME-sensitive relaxation, but did not evoke the second component of iNANC-mediated relaxation, indicating that the threshold for activation of the initial component is different from that of the second component [8]. It is possible that NO can be released preferentially according to the amplitude of the efferent nerve reflex activation.

In human airways, no evidence has been found for inhibitory adrenergic innervation and the iNANC system was reported to be the principal inhibitory system for the smooth muscles [4]. Relaxation mediated by iNANC neurons has been also demonstrated in vivo in healthy subjects and can be activated by inhalation of capsaicin $[28,29]$ or sulphur dioxide [30], or by laryngeal stimuation [31]. Although the iNANC system seems to be important in airway disease, its precise role remains uncertain. In asthmatic subjects, it has been reported that the iNANC system may play a crucial role in nocturnal asthma because iNANC-mediated relaxation was reduced in the early morning [32]. However, other investigators have found no difference in the amplitude of iNANC-mediated relaxation between healthy and asthmatic subjects and have concluded that the contribution of the iNANC system to the pathogenesis of asthma was not important [29]. Further in vivo investigation is required to elucidate the precise role of iNANC in airway disease.

NO is produced by a variety of cells within the respiratory tract, including epithelial and inflammatory cells. It has been reported that an inducible isoform of NO synthase (iNOS) is expressed in epithelial cells after exposure to cytokines such as tumour necrosis factor- $\alpha$, interleukin$1 \beta$, and interferon- $\gamma$ [33]. The iNOS has a much greater capacity to produce NO than the constitutive NOS (cNOS), and may be involved in airway inflammation. Also, exhaled NO has been shown to be increased in inflammatory airway diseases [34, 35]. These observations suggest that NO derived from iNOS may facilitate airway inflammation. Further study is necessary to elucidate the interaction of NO derived from iNOS with NO released from iNANC neurons and the resulting effect on airway hyperresponsiveness.

In this study, hexamethonium significantly decreased blood pressure, and L-NAME significantly increased the blood pressure. The possibility that the changes in blood pressure might influence the present results could not be entirely excluded. In rats, L-NAME caused significant increases in blood pressure, however it did not increase airway responsiveness [36]. It has been also reported that raising systemic blood pressure with phenylephrine did not potentiate vagally-induced bronchoconstriction [27]. In addition, L-NAME increased blood pressure, but it did not affect airway permeability $[37,38]$. These observations suggest that the increase in blood pressure caused by LNAME did not cause airway hyperresponsiveness by itself.

In summary, results of this study suggest that nitric oxide is released from inhibitory nonadrenergic noncholinergic nerve terminals in the airways of the cat. Nitric oxide appears to be released by a reflex mechanism and suppresses airway responsiveness to inhaled serotonin aerosol. Absence of nitric oxide-induced bronchodilation may be involved in the induction of airway hyperresponsiveness. Further investigation is needed to elucidate the pathophysiological role of nitric oxide in airway disease.

\section{References}

1. Boushey HA, Holtzman MJ, Sheller JR, Nadel JA. Bronchial hyperreactivity. Am Rev Respir Dis 1980; 121: 389413.

2. Barnes PJ. Neural control of human airways in health and disease. Am Rev Respir Dis 1986; 134: 1289-1314.

3. Coburn RF, Tomita T. Evidence for nonadrenergic inhibitory nerves in the guinea pig trachealis muscle. $\mathrm{Am} \mathrm{J}$ Physiol 1973; 224: 1072-1080.

4. Richardson J, Belend J. Nonadrenergic inhibitory nervous system in human airways. J Appl Physiol 1976; 41: 764 771.

5. Diamond L, O'Donnell M. A nonadrenergic vagal inhibitory pathway to feline airways. Science 1980; 208: 185188.

6. Irvin CG, Boileau R, Tremblay J, Martin RR, Macklem PT. Bronchodilatation: noncholinergic, nonadrenergic mediation demonstrated in vivo in the cat. Science 1980; 207: 791-792.

7. Li CG, Rand MJ. Evidence that part of the NANC relaxant response of guinea-pig trachea to electrical field stimulation is mediated by nitric oxide. Br J Pharmacol 1990; 102: 91-94.

8. Takahashi N, Tanaka $\mathrm{H}$, Abdulla N, Jing L, Inoue R, Ito Y. Regional difference in the distribution of L-NAMEsensitive and -insensitive NANC relaxations in cat airway. J Physiol 1995; 488: 709-720.

9. Belvisi MG, Stretton $\mathrm{CD}$, Miura $\mathrm{M}$, et al. Inhibitory NANC nerves in human tracheal smooth muscle: a quest for the neurotransmitter. J Appl Physiol 1992; 73: 25052510 .

10. Jing L, Inoue R, Tashiro K, Takahashi S, Ito Y. Role of nitric oxide in non-adrenergic, non-cholinergic relaxation and modulation of excitatory neuroeffector transmission in the cat airway. $J$ Physiol 1995; 483: 225-237.

11. Tucker JF, Brave SR, Charalambous L, Hobbs AJ, Gibson A. L-NG-nitro arginine inhibits non-adrenergic, non-cholinergic relaxations of guinea-pig isolated tracheal smooth muscle. Br J Pharmacol 1990; 100: 663-664.

12. Fisher JT, Anderson JW, Waldron MA. Nonadrenergic noncholinergic neurotransmitter of feline trachealis: VIP or nitric oxide? J Appl Physiol 1993; 74: 31-39.

13. Aizawa H, Tanaka H, Sakai Z, Takata S, Hara N, Ito Y. LNAME-sensitive and -insensitive NANC relaxation in the cat airway in vivo and in vitro. Eur Respir J 1997; 10: 314-321.

14. Bai TR, Macklem PT, Martin JG. The effects of parasympathectomy on serotonin-induced bronchoconstriction in the cat. Am Rev Respir Dis 1986; 133: 110-115.

15. Hahn HL, Wilson AG, Graf PD, Fischer SP, Nadel JA. Interaction between serotonin and efferent vagus nerves in dog lungs. J Appl Physiol 1978; 44: 144-149.

16. Aizawa H, Matsuzaki Y, Ishibashi M, Domae M, Hirose $\mathrm{T}$, Tanaka K. A possible role of nonadrenergic inhibitory nervous system in airway hyperreactivity. Respir Physiol 1982; 50: 187-196.

17. Amdur MO, Mead J. Mechanics of respiration in unanesthetized guinea-pigs. Am J Physiol 1958; 192: 364-368.

18. McMahon TJ, Hood JS, Nossaman BD, Kadowitz PJ. Analysis of responses to serotonin in the pulmonary vascular bed of the cat. J Appl Physiol 1993; 75: 93-102. 
19. McMahon TJ, Hood JS, Bellan JA, Kadowitz PJ. $N^{\omega}$ nitro-L-arginine methyl ester selectively inhibits pulmonary vasodilator responses to acetylcholine and bradykinin. J Appl Physiol 1991; 71: 2026-2031.

20. McMahon TJ, Ignarro LJ, Kadowitz PJ. Influence of zaprinast on vascular tone and vasodilator responses in the cat pulmonary vascular bed. $J$ Appl Physiol 1993; 74: 1704-1711.

21. Nijkamp FP, van der Linde HJ, Folkerts G. Nitric oxide synthesis inhibitors induce airway hyperresponsiveness in the guinea pig in vivo and in vitro. Role of the epithelium. Am Rev Respir Dis 1993; 148: 727-734.

22. Folkerts G, Linde HJL, Nijkamp FP. Virus-induced airway hyperresponsiveness in guinea pigs is related to a deficiency in nitric oxide. J Clin Invest 1995; 95: 26-30.

23. Chesrown SE, Venugopalan CS, Gold WM, Drazen JM. In vivo demonstration of nonadrenergic inhibitory innervation of the guinea pig trachea. J Clin Invest 1980; 65: 314-320.

24. Clerici C, Macquin-Mavier I, Harf A. Nonadrenergic bronchodilation in adult and young guinea pigs. $\mathrm{J} \mathrm{Appl}$ Physiol 1989; 67: 1764-1769.

25. Lundberg JM, Lundblad L, Martling CR, Saria A, Stjarne $\mathrm{P}$, Anggard A. Coexistence of multiple peptides and classic transmitters in airway neurons: functional and pathophysiologic aspects. Am Rev Respir Dis 1987; 136: S1622.

26. Lundberg JM. New aspects on airway innervation. Pharmacol Toxicol 1993; 72: Suppl. 3, 21-27.

27. Lei YH, Barnes PJ, Rogers DF. Regulation of NANC neural bronchoconstriction in vivo in the guinea-pig: involvement of nitric oxide, vasoactive intestinal peptide and soluble guanylyl cyclase. Br J Pharmacol 1993; 108: 228-235.

28. Ichinose $\mathrm{M}$, Inoue $\mathrm{H}$, Miura $\mathrm{M}$, Yafuso $\mathrm{N}$, Nogami $\mathrm{H}$, Takishima T. Possible sensory receptor of nonadrenergic inhibitory nervous system. J Appl Physiol 1987; 63: 923929.
29. Lammers JWJ, Minette P, McCusker MT, Chung KF, Barnes PJ. Capsaicin-induced bronchodilation in mild asthmatic subjects: possible role of nonadrenergic inhibitory system. J Appl Physiol 1989; 67: 856-861.

30. Thompson DC, Szarek JL, Altiere RJ, Diamond L. Nonadrenergic bronchodilation induced by high concentrations of sulphur dioxide. J Appl Physiol 1990; 69: 1786-1791.

31. Michoud MC, Amyot R, Jeanneret-Grosjean A, Couture J. Reflex decrease of histamine-induced bronchoconstriction after laryngeal stimulation in humans. Am Rev Respir Dis 1987; 136: 618-622.

32. Mackay TW, Fitzpatrick MF. Non-adrenergic, non-cholinergic nervous system and overnight airway calibre in asthmatic and normal subjects. Lancet 1991; 338: 12891292.

33. Kharitonov SA, Yates D, Robbins RA, Logan-Sinclair R, Shinebourne EA, Barnes PJ. Increased nitric oxide in exhaled air of asthmatic patients. Lancet 1994; 343: 133135.

34. Kharitonov SA, O'Connor BJ, Evans DJ, Barnes PJ. Allergen-induced late asthmatic reactions are associated with elevation of exhaled nitric oxide. Am J Respir Crit Care Med 1995; 151: 1894-1899.

35. Kharitonov SA, Yates DH, Barnes PJ. Inhaled glucocorticoids decrease nitric oxide in exhaled air of asthmatic patients. Am J Respir Crit Care Med 1996; 153: 454-457.

36. Kips JC, Lefebvre RA, Peleman RA, Joos GF, Pauwels RA. The effect of a nitric oxide synthase inhibitor on the modulation of airway responsiveness in rats. Am J Respir Crit Care Med 1995; 151: 1165-1169.

37. Kuo HP, Liu S, Barnes PJ. The effect of endogenous nitric oxide on neurogenic plasma exudation in guinea-pig airways. Eur J Pharmacol 1992; 221: 385-388.

38. Miura M, Ichinose M, Kageyama N. Endogenous nitric oxide modifies antigen-induced microvascular leakage in sensitized guinea pig airways. J Allergy Clin Immunol 1996; 98: 144-151. 